\title{
25 Research Soure \\ Oleic Acid Reduces Brain Injury by Oxidative Stress Induced by Some Anticancer Drugs in Rat Brain
}

\author{
David Calderón Guzmán \\ Instituto Nacional de Pediatria \\ Norma Osnaya Brizuela \\ Instituto Nacional de Pediatria \\ Maribel Ortíz Herrera \\ Instituto Nacional de Pediatria \\ Hugo Juarez Olguin ( $\nabla$ juarezol@yahoo.com ) \\ Instituto Nacional de Pediatria https://orcid.org/0000-0002-1405-1728 \\ Francisca Trujillo Jimenez \\ Instituto Nacional de Pediatria \\ Armando Valenzuela Peraza \\ Instituto Nacional de Pediatria \\ Gerardo Barragán Mejía \\ Instituto Nacional de Pediatria
}

Research article

Keywords: Anticancer; Brain; Nitropropionic acid, oxidative damage

Posted Date: February 28th, 2020

DOI: https://doi.org/10.21203/rs.3.rs-15472/v1

License: (c) (i) This work is licensed under a Creative Commons Attribution 4.0 International License. Read Full License 


\section{Abstract}

Background: Oleic acid (OA) is a monounsaturated compound with many health-benefitting properties such as obesity prevention, increased insulin sensitivity, antihypertensive and immune-boosting properties, etc. Within the untold benefits of this fatty acid is the novelty of anticancer property. OA can interact with cancer cell proteins and increase cancer cell proliferation-inhibiting factors; thus, turning down their potentials to spread to other tissues.

Purpose: The proposal in the present work was to carry out a factual analysis on how oleic acid (OA) and some anticancer drugs offset nitropropionic acid-induced oxidative stress .

Methods: Thirty Wistar rats were recruited and divided into five groups A, B, C, D and E; and made to take anticancer drugs in combination with $\mathrm{OA}$ in the following forms: Group $\mathrm{A}$, (control) $0.9 \%$ of sodium chloride $(\mathrm{NaCl})$; group $\mathrm{B}$, oleic acid ( $\mathrm{OA}$ ) only ; group $\mathrm{C}$, cyclophosphamide (CPP) + OA; group D, daunorrubicine (DRB) + OA; and group E, dexrazoxane (DXN) + OA. Every treatment was by intraperitoneal route and the administration was every $24 \mathrm{~h}$ for 5 days. The measurement of lipid peroxidation products, reactive oxygen species, sodium-potassium pump, antioxidants and amines were performed from brain extracts of the animals using TBARS, H 202 , $\mathrm{Na}+, \mathrm{K}+$ ATPase activity, GSH and dopamine (DA) respectively. Glucose hemoglobin and triglycerides were measured in blood.

Results: In cortex, GSH increased in all groups, except in group B. Group C showed the highest increase of this biomarker. TBARS decrease and dopamine increase in all regions of groups C, D and E. H 202 increased only in cerebellum/medulla oblongata of group D and E. ATPase expression decreased in striatum of group C. Glucose increased in group E and hemoglobin increased in groups C and D.

Conclusions: The boost in the amine (DA) and the antioxidant (GSH) generated by OA administration depicts that brain damage due to anticancer drugs could be ameliorated when jointly given with $O A$.

\subsection{Background}

Worldwide increase in obesity prevalence across age groups has remained unabated in different countries [1, 2]. In Mexico, this tendency has continued to rise until date, affecting both young and old [2,3]. Metabolic syndrome (MS) is a group of conditions characterized high abdominal fat accumulation, high systolic and diastolic blood pressure, high density lipid cholesterol, and high blood glucose and triglycerides [2,4]. Irrational consumption of fatty foods and meats has been linked with oxidative stress with its concomitant adverse health effects and as an important risk factor for the development of cancer [2,5]. In Mexico, oncological diseases rank second as the principal cause of death in the general population. The toll of cancer mortality in the country had been witnessing an increase since 1953 in such way that by 1998 , it had registered an accumulated rise of $68 \%$, a figure that may have increased today. Likewise, in recent years, malignant tumor morbidity has gone up as depicted in the '90s report where it was shown that malignant tumor in adult females and males of 30 years old rose to $63.5 \%$ and $35.3 \%$ respectively [2,6]. Besides, malignant tumors have been reckoned as the main cause of death in pediatric population under 15 years old [2,7]. The treatment most widely used in cancer therapy focuses on drugs that target on fast growing and dividing cancerous cells and most of these drugs have been associated to an increase in monoamine concentrations in the brain $[2,8]$. In any case, these drugs eliminate these cells in specific points of cell cycle [2,9]. One of the principal side effects of chemotherapeutic drugs is MS [2,10]. In Mexico, childhood obesity is today a preoccupying problem of health $[2,11]$. In our country, chemotherapy protocols employed in childhood cancer treatments generally includes anticancer agents [2,12]. It has been reported that exogenous polyunsaturated fatty acids such as oleic and linoleic acids can temper the cytotoxic activity of anti-cancer drugs [2,13], and dexrazoxane has been used to protect the heart against cardiotoxic side effects of anthracyclines [14].

The anti-cancer properties of OA have been demonstrated. OA can interact with cancer cell proteins and increase cancer cell proliferationinhibiting factors; thus, turning down their potentials to spread to other tissues. However, the administration of OA may generate nitric oxide (NO) [2,15]; in the form of nitro-oleic acid (OA-NO2); a nitric oxide-derived endogenous lipid product - likely via its anti-inflammatory and antioxidant properties $[2,16]$. NO is a neuromodulator and in high concentrations leads to cell damage by the formation of nitrosoglutathione (NOGSH) or by oxidative stress [2,17]. Oxidative stress due to nitric oxide is the main cause of alterations in the mitochondrial ultrastructure and DNA damage [18,19]. This damage is the primary event in 3-nitropropionic acid toxicity.

Free radicals (FR) are deleterious to cell components [2,20], especially the lipid bilayer of the plasma membrane [21]. The CNS not only mediates in the regulation of appetite and free radicals generation but also actively takes part in the control of the metabolic functions of these [2,22]. 
Cell membrane alterations dependent on mechanical changes that principally involve the lipid bilayer are known to influence different biological processes [2,23], and modulate energy and glucose homeostasis via the activation of dopaminergic systems of the hypothalamic neurocircuits and higher brain circuits $[2,24]$. The lipid bilayer of the neurons contains structural proteins that are contiguous with brain plasma membrane phospholipids [2,25]. This permits ionic interchange between these two structures, fueled by the stimulating action of $\mathrm{Na}+\mathrm{K}+$ ATPase that boosts $\mathrm{Na}+$ and $\mathrm{K}+$ flows through the bilayers $[2,26]$. The main effect of $\mathrm{Na}+, \mathrm{K}+\mathrm{ATPase}$ inhibition is the release of excitatory amino acid which can be injurious to the CNS [2,27].

Based on this background, this work aims to analyze the effect of oleic acid and some anticancer drugs as cyclofosfamide, daunorrubicine and dexrazoxane (a cardioprotector) against NPA-induced oxidative stress and the levels of dopamine in rat brain.

\subsection{Materials And Methods}

Thirty Wistar rats - gender male; age 3 months and average weight $100 \mathrm{~g}$ - were recruited for the study and equally divided into five groups $A, B, C, D$, and $E$. The treatments given to the animals consist of anticancer drugs in combination with OA. Group $A$ (control), received $\mathrm{NaCl} 0.9 \%$; group $B$, received only oleic acid $(\mathrm{OA})(1.5 \mathrm{ml} /$ rat); group C was given cyclophosphamide (CPP) $(20 \mathrm{mg} / \mathrm{rat})+$ $O A$; group D was administered daunorrubicine (DRB) $(4 \mathrm{mg} / \mathrm{rat})+\mathrm{OA}$; and group $\mathrm{E}$ was treated with dexrazoxane $(\mathrm{DXN})(50 \mathrm{mg} / \mathrm{rat})+\mathrm{OA}$. Every treatment was by intraperitoneal route and the administration was every $24 \mathrm{~h}$ for 5 days. The animals were procured from Bioterium of Metropolitan University of Mexico City and housed six per cage in clean plastic cages and allowed to acclimatize in the room environment for 1 day. Animals were maintained in a mass air displacement room with a 12-h light:12-h dark cycle at $22 \pm 2^{\circ} \mathrm{C}$ with a relative humidity of $50 \pm 10 \%$. Balanced food (Rodent diet 5001) and drinking water were given to the animals ad libitum. On the last day of the treatments, blood samples were obtained to measure glucose hemoglobin and triglycerides. After that, the rats were sacrificed by decapitation and their brains were extracted and sectioned into cortex, striatum, and cerebellum/medulla oblongata (CMO). We do not use anesthetics because they could alter our results. The sections were immediately immersed in $\mathrm{NaCl}$ at $0.9 \%$ and kept at $4^{\circ} \mathrm{C} .3 \mathrm{ml} \mathrm{of} \mathrm{tris-HCl}$ $0.05 \mathrm{M} \mathrm{pH} 7.2$ was employed in the homogenization of every section of the brain and used to assay the peroxidation of lipids (TBARS), $\mathrm{H}_{2} \mathrm{O}_{2}, \mathrm{Na}+, \mathrm{K}+$ ATPase activity, glutathione (GSH), and dopamine using previously validated methods. To avoid the degradation and loss of integrity of the samples, they were stored at $-20^{\circ} \mathrm{C}$ until analyzed. Animal management and care was conducted in accordance to the international guidelines for animal care and to the Mexican Guidelines Z00-062, and that allowed by the Laboratory of Animal Care Committee of The National Institute of Pediatrics.

Triglycerides, blood hemoglobin and glucose were measured at the end of the treatments. Glucose and triglyceride concentrations were measured with two sets of $20 \mu \mathrm{l}$ of volume non-anticoagulant tail-end blood samples using Accu-Chek glucose reactive paper (Roche Mannheim, Germany) and reported in $\mathrm{mg} / \mathrm{dl}$.

\subsubsection{Measurement of Dopamine (DA)}

DA concentrations were measured from a 9000 rpm 10 min centrifuged HCLO4 homogenized supernatant tissue. The centrifugation was done in a microcentrifuge (Hettich Zentrifugen, model Mikro 12-42, Germany), and the measurement was carried out based on Calderon et al $[2,28]$ method using FL Win Lab version 4.00 .02 software. The values were deduced from a previously standardized curve and reported as $\mathrm{nM} / \mathrm{g}$ of wet tissue.

\subsubsection{Glutathione (GSH) measurement}

To measure GSH levels, the homogenized tissue supernatant obtained prior to centrifugation for 5 min period at $9000 \mathrm{rpm}$ (Mikro 12-42, Germany centrifuge) using Hissin and Hilf modified method [2,29].

\subsubsection{Lipid peroxidation measurement}

The approach employed in the measurement of TBARS was Gutteridge and Halliwell modified technique [21]. A $1 \mathrm{ml}$ of the tris$\mathrm{HCl} 0.05 \mathrm{M} \mathrm{pH} 7.4$ brain homogenate was mixed with $2 \mathrm{ml}$ thiobarbaturic acid (TBA) that contains $1.25 \mathrm{~g}$ TBA, $40 \mathrm{~g}$ trichloroacetic acid (TCA) and $6.25 \mathrm{ml}$ of concentrated chlorhydric acid $(\mathrm{HCL})$ diluted in $250 \mathrm{ml}$ of deionized $\mathrm{H}_{2} \mathrm{O}$. The resulting mixture was heated to boiling point for 30min (Thermomix 1420) and cooled for $5 \mathrm{~min}$ in an ice bath. This was subjected to a centrifugation at $700 \mathrm{~g}$ for $15 \mathrm{~min}$ (Sorvall RC-5B Dupont). The floating tissue absorbances were spectrophotometrically (Helios-a de UNICAM) read in triplicate at 532nm. The concentration of reactive substances to the thiobarbaturic acid (TBARS) was expressed in $\mu \mathrm{M}$ of Malondialdehyde/g of wet tissue [30]. 
ATPase activity was assessed based on Calderón et al method [31]. One mg (10\%) w/v of the tris-HCl0. 05M pH 7.4 tissue homogenate was subjected to an incubation for $15 \mathrm{~min}$ in a solution containing $3 \mathrm{mM} \mathrm{MgCl} 2,7 \mathrm{mM} \mathrm{KCl}$ and $100 \mathrm{mM} \mathrm{NaCl} .4 \mathrm{mM}$ tris-ATP was added to the mixture and the incubation was repeated for another $30 \mathrm{~min}$ at $37^{\circ} \mathrm{C}$ in a shaking water bath (Dubnoff Labconco). The reaction was detained using $100 \mu \mathrm{L} 10 \%$ trichloroacetic acid w/v. The samples were final centrifuged at $100 \mathrm{~g}$ for $5 \mathrm{~min}$ at $40{ }^{\circ} \mathrm{C}$ [32]. Inorganic phosphate $(\mathrm{Pi})$ was measured in duplicates using one supernatant aliquot as reported by Fiske and Subarrow [33]. The reading of the absorbance of the supernatant of each sample was carried out spectrohpotometrically at $660 \mathrm{~nm}$ in a Helios-a, UNICAM and expressed as $\mathrm{mM} \mathrm{Pi/g}$ wet tissue per min.

\subsection{5 $\mathrm{H}_{2} \mathrm{O}_{2}$ determination}

$\mathrm{H}_{2} \mathrm{O}_{2}$ measurement was performed with Asru [34] and Hernandez [35] techniques after modification. The brain regions (cortex, striatum, $\mathrm{CMO}$ ) were separately diluted in $3 \mathrm{ml}$ of tris- $\mathrm{HCl} 0.05 \mathrm{M} \mathrm{pH} 7.4$ buffer and homogenized. $100 \mu \mathrm{l}$ of the resulting homogenate of each brain region was mixed with $1 \mathrm{ml}$ of potassium dichromate solution ( $\mathrm{K} 2 \mathrm{Cr} 2 \mathrm{O} 7$ ). The mixture was heated to boiling point for $15 \mathrm{~min}$ (Thermomix 1420 ) and cooled for $5 \mathrm{~min}$ in an ice bath. Then, the samples were subjected to a centrifugation at $3,000 \mathrm{~g}$ for $5 \mathrm{~min}$ (Sorvall RC-5B Dupont). The reading of the floating absorbances was spectrophotometrically done in triplicate at 570nm (He?ios-?, UNICAM). $\mathrm{H}_{2} \mathrm{O}_{2}$ concentration was expressed in $\mu$ Moles [30].

\subsubsection{Statistical analysis}

For statistical analysis, the fisher estimation test (ANOVA) and the nonparametric test of Kruskal-Wallis were used with their corresponding contrasts and previous to variance homogeneity comparison. Statistical significance was put at p-values of $<0.05[2,36]$. JMP Statistical Discovery Software, version 8.0 .0 from SAS was employed in the statistical tests [2].

\subsection{Results}

\subsubsection{GSH}

In the cortex, GSH was observed to increase in all the groups except in the group treated with OA alone. The increase in this bioamine was highest in the group that received CPP + OA when compared with the control group and all other groups. On the other hand, a decrease was appreciated in GSH levels in the striatum of the animal group treated with OA. However, this event showed a significant difference only with the group that received CPP + OA where a greater decrement was observed. In CMO region, GSH increased in the groups that were administered $D R B+O A$ and $C P P+O A$ with this having statistically significant difference on comparing it with the groups of $O A$ and CDX + OA (table 1).

\subsubsection{TBARS}

The peroxidation of lipids witnessed a significant decrease in the cortex, striatum, and cerebellum/medulla oblongata (CMO) of the treated groups. Data analysis depicted that the reduction in TBARS levels was significant when the groups that received OA, CDX + $\mathrm{OA}, \mathrm{CPP}+\mathrm{OA}$ and $\mathrm{DRB}+\mathrm{OA}$ were compared with the control group. The same significant effect was observed on comparing $C D X+O A$, $\mathrm{CPP}+\mathrm{OA}$ and $\mathrm{DRB}+\mathrm{OA}$ groups with the group that received only OA. In this brain region, a significant difference in TBARS levels was also observed between $C D X+O A$ group vs. DRB + OA group, which showed the least lipid peroxidation (table 1).

\subsubsection{Dopamine}

The concentration of this neurotransmitter increased ten folds in the groups treated with drug combinations CDX + OA, CPP +OA and DRB $+O A$ in the three brain regions studied with respect to control and OA groups. Additionally, statistically significant differences were appreciated on comparing the group $C D X+O A$ vs the group $D R B+O A$ in the cortex and DRB + OA vs. CPP + OA in the striatum. In none of the regions were differences observed between the control group and OA group (table 1).

\subsection{4 $\mathrm{H}_{2} \mathrm{O}_{2}$}

With respect to $\mathrm{H}_{2} \mathrm{O}_{2}$, data analysis revealed significant changes consisting of an increase in the levels of this indicator in the $\mathrm{CMO}$ brain region attributable to the treatments with $C D X+O A$ and $D R B+O A$ with respect to the group of control and the OA group (table 1). 


\subsubsection{ATPase}

ATPase activity was only seen to be affected in the striatum regions where a significant

reduction in the enzyme activity was observed in the CPP + OA group in comparison with the control group and the group treated with $C D X+O A$. The levels of glucose showed significant increase in the group that was administered the combination of $C D X+O A$ (table 2). Hemoglobin increased in $C P P+O A$ and $D R B+O A$ groups. Although this indicator increased in the group treated with $C D X+O A$, this was not significant when compared with the control group (table 2). With respect to triglycerides, differences between the control group and the rest of the treated groups were not observed (table 2).

\subsection{Discussion}

Drugs that are used in the treatment of cancer usually have adverse impacts on brain functions. The neurological side effects of these drugs have been widely reported in peripheral neuropathy and encephalopathy $[2,8]$. In this study, the results indicated that CDX, CPP and DRB increased dopamine levels in cortex, striatum and CMO in the animals. However, in the group treated with OA, the biomarkers evaluated in this study did not witness any changes. This may be explained either by alterations in the metabolic processes of OA or that the deacylation/acylation reactions of this acid were inhibited and this triggers an increase in the markers of oxidative stress and dysfunction of the mitochondria in dopaminergic neurons [2,37]. Hemoglobin levels increased in the groups treated with CPP and DRB in combination with $\mathrm{OA}$, except in the group treated with CDX. Probably this may be owed to the fact that the antioxidant actions of CDX are totally dependent on its metabolism that yields hydrolyzed open-ringed product or because CDX does not have any effect on the ironindependent oxygen free radical production [38], and on the increase in the levels of glucose. ATPase activity increased in striatum region in the group treated with CPP + OA. Similar results were found in the antioxidant enzymes of animals treated with CPP and OA / linoleic acids, suggesting a reduction in the oxidative stress [39]. This finding coincides with the studies of Park et al [40], who suggested that fatty acids (linoleic acid, oleic acid and palmitic acid), inhibit the increase in [Ca2+], ROS generation and apoptosis with a similar potency, and as consequence may ameliorate toxicity of the anticancer drugs. Nitro-oleic acid (OA-NO2) is an electrophilic nitroalkenyl fatty acid with several attractive signaling properties. In healthy human blood, the concentration is found to be $\sim 0.6 \mu \mathrm{M}[41]$, and its increased production is demonstrated during inflammatory and metabolic stress [42]. Baraldi et al [43], which suggests that conjugated linoleic acid (CLA) reduces the accumulation of body fat and increases body metabolism. In the groups that received oleic acid, lower lipid accumulation was found to be reversed aided by the increase in PPAR gamma content. In the same way, high ROS generation was reversed in this group; thus, improving the oxidative status. Studies have shown that the percentage of cell membrane content of free fatty acid is lower than $5 \%$ and that any excess is rapidly incorporated into phospholipids $[2,44]$. These findings are supported by Hilvo et al [45], who suggested that the alterations in OA levels in the blood in patients with breast cancer are associated with their response to chemotherapy [2]. In the case of oncological agents as DRB and CPP as well as CDX, a cardioprotector, GSH levels increased in the cortex, and CMO when rats were treated with $\mathrm{CPP}+\mathrm{OA}$ [35]. Besides, there was a decrease in lipoperoxidation levels in cortex, striatum and medulla oblongata with the combination of oleic acid.

The blood-brain barrier, formed by the tight junctions within the capillary endothelium of the vertebrate brain, discriminates the access of several molecules to the brain tissue [2,25]. The brain is the most consumer of oxygen in the body and therefore has a high level of oxidant production; however, its protective antioxidant mechanisms is weak. Oxidative stress hampers lipid metabolism at various levels ranging from benign lipid storage to so-called second hit of inflammation activation, and thereby induces lipid overload [2,46]. Hence, substances that can modulate the prooxidant-antioxidant balance would provide a therapeutic option to enhance neuroprotection in response to oxidative stress $[2,47]$ produced by nitropropionoic acid [48].

\section{Conclusion}

Oleic acid, as depicted by the results of this work, increases dopamine and antioxidant defense; thus, it can mellow down the oxidative side effects of oncological agents and in this way, can protect the brain from the injurious impact of these agents.

In the light of the above, food supplements such as OA could be a potential strategy to offset the adverse effects of anticancer drugs during chemotherapy in pediatric population. Nevertheless, more studies with different animal models are needed to demonstrate OA neuroprotective mechanism and potential, not only during treatment with anticancer drugs but also in other health conditions.

\section{Abbreviations}


CNS. Central Nervous System

DA. Dopamine

DNA. Deoxyribonucleic acid

FR. Free radicals

GSH. Glutathione

NOGSH. nitroso-glutathione

3-NPA. 3-nitropropionic acid

L-DOPA. L-3,4-dihydroxyphenylalanine

OPT. ortho-phthaldehyde

RNS. Reactive nitrogen Species

ROS. Reactive Oxygen Species

TBARS. Thiobarbituric acid reactive substances

\section{Declarations}

Ethics approval and consent: Animal management and care was conducted in accordance to the international guidelines for animal care and to the Mexican Guidelines Z0O-062, and that allowed by the laboratory animal care committee of our Institution.

Consent to publish: Not applicable.

Availability of data and material: The data sets used and/or analyzed in the present study are available from the corresponding author only on reasonable request.

Competing interests: The authors declare that they have no competing interests.

Funding: This manuscript was not funded by any organization.

Authors' contributions: $\mathrm{DCG}^{\mathrm{a}, \mathrm{c}, \mathrm{d}, \mathrm{e}}, \mathrm{NOB}^{\mathrm{b}, \mathrm{d}, \mathrm{e}}, \mathrm{MOH}^{\mathrm{b}, \mathrm{d}, \mathrm{e}}, \mathrm{HJO}^{\mathrm{c}, \mathrm{d}, \mathrm{e}}, \mathrm{FTJ} \mathrm{b}^{\mathrm{b}, \mathrm{d}, \mathrm{e}}, \mathrm{AVP}^{\mathrm{b}, \mathrm{d}, \mathrm{e}}, \mathrm{GBM}^{\mathrm{b}, \mathrm{d}, \mathrm{e}}$

(a) Contributed in the conception and design. (b) Contributed in the acquisition, analysis and interpretation of data. (c) Critically revised the manuscript for important intellectual content. (d) Drafted manuscript. (e) Gave final approval.

Acknowledgment: We thank Dr. Cyril Ndidi Nwoye, a native English speaker and language professor, for the critical review and translation of this manuscript. We are very grateful to National Institute of Pediatrics, Mexico City for the provision of Federal Resources to support this work.

\section{References}

1. Mnafgui K, Derbali A, Sayadi S, Gharsallah N,Elfeki A,Allouche N. Anti-obesity and cardioprotective effects of cinnamic acid in high fat diet- induced obese rats. J Food Sci Technol 2015; 52:4369-4377.

2. Calderón Guzmán D, Osnaya Brizuela N, Ortiz Herrera M, Juarez Olguin H, Hernández García E, Valenzuela Peraza A, et al. Oleic acid protects against oxidative stress exacerbated by cytarabine and doxorubicin in rat brain. Anti-Cancer Agents ME2016; 16(11):14911495.

3. National Health Survey (NHS) Obesity between persons attended in IMSS. Medical Rev IMSS 2004; 42:239-45.

4. Bruno E, Gargano G, Villarini A, Traina A,Johansson H,Mano MP, et al. Adherence to WCRF/AICR cancer prevention recommendations and metabolic syndrome in breast cancer patients. Int J Cancer 2015, Jul 14.doi: 10.1002/ijc.29689. 
5. Bishop KS, Erdrich S, Karunasinghe N, Han DY,Zhu S, Jesuthasan A, et al. An investigation into the association between DNA damage and dietary fatty acid in men with prostate cancer. Nutrients 2015; 7(1):405-422.

6. The increment of cancer incidence in children. 2006. http://www.healthdata.org/mexico.

7. Ross JA, Severson RK, Pollock BH, Robison LL. Childhood cancer in the Unites States. A geographical analysis of cases from the pediatric cooperative clinical trials groups. Cancer 1996; 77:201-207.

8. Matsutani T, Tamaru M, Hayakawa Y, Nagayoshi M, Nakahara T, Tsukada Y. A neurochemical study of developmental impairment of the brain caused by the administration of cytosine arabinoside during the fetal or neonatal period of rats. Neurochem Res 1983; 8:1295-1306.

9. The Merck Manual of Diagnosis and Therapy. Eighteenth Edition. Merck \& Co. INC. NJ. USA. 2005.

10. Herrera-Silva JC, Treviño-Moore A, López-Beltran AL. Metabolic syndrome in patients with cancer during chemotherapy treatment. Medical Bull Infantil Hospital Mexico 2008; 65:110-120.

11. Sánchez-Castillo C, Pichardo-Ontiveros E, López RP. The epidemiology of obesity. Gaceta Medica Mexico 2004; 140:S6-S18.

12. Calderón GD, Juárez $\mathrm{OH}$, Guevara ZA, Juárez JA,Segura AL,Barragán MG, et al. Comparison between types of cancer chemotherapies used in a private and a government-based hospital in Mexico. Proc West Pharmacol Soc 2009; 52:26-29.

13. Germain E, Chajès V, Cognault S, Lhuillery C, Bougnoux P. Enhancement of doxorubicin cytotoxicity by polyunsaturated fatty acids in the human breast tumor cell line MDA-MB-231: relationship to lipid peroxidation. Int J Cancer 1998; 75:578-583.

14. Lipshultz SE, Rifai N, Dalton VM,Levy DE,Silverman LB, Lipsitz SR. The effect of dexrazoxane on myocardial injury in doxorubicintreated children with acute lymphoblastic leukemia. New Eng J Med 2004; 351:145-153.

15. Ruggiero M, Ward E, Smith R, Branca JJ,Noakes D,Morucci G. et al. Oleic acid, deglycosylated vitamin D-binding protein, nitric oxide: a molecular triad made lethal to cancer. Anticancer Res 2014; 34:3569-3578.

16. Liu S, Jia Z, Zhou L, Liu Y,Ling H,Zhou SF, et al. Nitro-oleic acid protects against adriamycin-induced nephropathy in mice. Am J Physiol Renal Physiol 2013; 305(11):F1533-41.

17. Hogg N, Singh RJ, Kalyanaraman B. The role of glutathione in the transport and catabolism of nitric oxide. FEBS Let 1996; 382:223228.

18. Aliev G, Obrenovich ME, Tabrez S, Jabir NR,Reddy VP,Li Y, et al. Link between cancer and Alzheimer disease via oxidative stress induced by nitric oxide-dependent mitochondrial DNA overproliferation and deletion. Oxid Med Cell Longev 2013; 962984 . doi: $10.1155 / 2013 / 962984$.

19. Calderón Guzmán D, Osnaya Brizuela D, Ortiz Herrera M, Juárez Olguín H,Valenzuela Peraza A,Hernández García E, et al. Folic acid increases levels of GHS in brain of rats with oxidative stress induced with 3-nitropropionic acid. Arch Physiol Biochem 2018; Sep 29, $1-6$.

20. Beckman JS, Beckman TW, Chen J, Marshall PA, Freeman BA. Apparent hydroxyl radical production by peroxynitrite: Implications for endothelial injury from nitric oxide and superoxides. Proc Natl Acad Sci USA 1990; 87:1624-1629.

21. Gutteridge JM, Halliwell B. The measurement and mechanism of lipid peroxidation in biological systems. Trends Biochem Sci 1990; 15:129-135.

22. Driver AS, Kodavanti PR, Mundy WR. Age-related changes in reactive oxygen species production in rat brain homogenates. Neurotoxicol Teratol 2000; 22:175-181.

23. Shamitko-Klingensmith N, Molchanoff KM, Burke KA, Magnone GJ, Legleiter J. Mapping the mechanical properties of cholesterolcontaining supported lipid bilayers with nanoscale spatial resolution. Langmuir 2012; 28:13411-13422.

24. Vogt MC, Brüning JC. CNS insulin signaling in the control of energy homeostasis and glucose metabolism - from embryo to old age. Trends Endocrinol Metab 2012; 24(2):76-84.

25. Swapna I, Sathya KV, Murthy CR, Senthilkumaran B. Membrane alterations and fluidity changes in cerebral cortex during ammonia intoxication. Neurotoxicology 2005; 335:700-704.

26. Stefanello FM, Chiarani F, Kurek AG. Methionine alters $\mathrm{Na}^{+}, \mathrm{K}^{+}$ATPase activity, lipid peroxidation and nonenzymatic antioxidant defences in rat hippocampus. Int J Develop Neurosci 2005; 23:651-656.

27. Calderon GD, Juarez OH, Hernandez GE, Labra RN, Barragán MG, Trujillo JF, et al. Effect of an antiviral and vitamins A,C,D on dopamine and some oxidative stress markers in rat brain exposed to ozone. Arch Biol Sci 2013; 65:1371-1379.

28. Calderón GD, Osnaya BN, García AR, Hernández GE, Guillé PA. Levels of glutathione and some biogenic amines in the human brain putamen after traumatic death. Proc West Pharmacol Soc 2008; 51:25-32.

Page $7 / 10$ 
29. Hissin PJ, Hilf R. A flurometric method for determination of oxidized and reduced glutathione in tissue. Anal Biochem 1974; 4:214226.

30. Guzmán CD, Osnaya NB, Ortíz MH, Valenzuela SP, Juárez-Olguín H,Mejía GB. Insulin plus zinc induces a favorable biochemical response effects on oxidative damage and dopamine levels in rat brain. Int J Biol Macromol2019; 132:230-235.

31. Calderon-Guzman D, Espitia-Vázquez I, López-Domínguez A, Hernández-García E, Huerta-Gertrudis B, Juárez-Olguín H. Effect of toluene and nutritional status on serotonin, lipid peroxidation levels and $\mathrm{Na}^{+} / \mathrm{K}^{+}$ATPase in adult rat brain. Neurochem Res 2005; 30:619-624.

32. Guzmán DC,Herrera MO,Brizuela NO, Mejía GB, Olguín HJ, Peraza AV. Trace elements cause oxidative damage in the brain of rats with induced hypotension. Auton Neurosci 2017; 208:113-116.

33. Fiske CH, Subbarow Y. The colorimetric determination of phosphorus. J Biol Chem 1972; 66:375-400.

34. Asru KS. Colorimetric assay of catalase. Anal Biochem 1972; 47:389-394.

35. Hernández García E, Calderón Guzmán D, Juárez Olguín H, Trujillo Jiménez F, Nuñez Acosta E, Pierdant Rioja F, et al. Effect of cerebrolysin on the levels of glutathione and $5-\mathrm{HT}$ in different regions of rat brain in presence of dantrolene. Biomed Aging Pathol 2011; 1:169-174.

36. Castilla-Serna L. Statistical guide for health science. Editorial Trillas. $1^{\circ}$ Edición. 2011, México, D.F.

37. Sánchez Campos S, Rodríguez Diez G, Oresti GM, Salvador GA. Dopaminergic neurons respond to iron-induced oxidative stress by modulating lipid acylation and deacylation cycles. PLoS One 2015; 10(6):e0130726.

38. Junjing Z, Yan Z, Baolu Z. Scavenging effects of dexrazoxane on free radicals. J Clin Biochem Nutr 2010; 47(3):238-245.

39. Tian H, Yan H, Tan S, Zhan P,Mao X, Wang P, et al. Apricot kernel oil ameliorates cyclophosphamide-associated immunosuppression in rats. Lipids 2016; 51(8):931-939.

40. Park KH, Kim SY, Gul R, Kim BJ,Jang KY,Chung HT. et al. Fatty acids ameliorate doxorubicin-induced intracellular ca2+ increase and apoptosis in rat cardiomyocytes. Biol Pharm Bull 2008; 31(5):809-815.

41. Baker PR, Lin Y, Schopfer FJ, Woodcock SR,Groeger AL,Batthyany C, et al. Fatty acid transduction of nitric oxide signaling: multiple nitrated unsaturated fatty acid derivatives exist in human blood and urine and serve as endogenous peroxisome proliferatoractivated receptor ligands. J Biol Chem 2005; 280:42464-42475.

42. Baker PR, Schopfer FJ, O'Donnell VB, Freeman BA. Convergence of nitric oxide and lipid signaling: anti-inflammatory nitro-fatty acids.Free Radic Biol Med 2009; 46:989-1003.

43. Baraldi F, Dalalio F, Teodoro B, Prado I, Curti C, Alberici L. Body energy metabolism and oxidative stress in mice supplemented with conjugated linoleic acid (CLA) associated to oleic acid. Free Radic Biol Med 2014; 75 Suppl 1:S21.

44. Piotto S, Trapani A, Bianchino E, Ibarguren M,López DJ,Busquets X, et al. The effect of hydroxylated fatty acid-containing phospholipids in the remodeling of lipid membranes. Biochim Biophys Acta 2014; 1838:1509-1517.

45. Hilvo M, Gade S, Hyötyläinen T, Nekljudova V,Seppänen-Laakso T,Sysi-Aho M, et al. Monounsaturated fatty acids in serum triacylglycerols are associated with response to neoadjuvant chemotherapy in breast cancer patients. Int J Cancer 2014; 134:17251733.

46. Popa-Wagner A, Mitran S, Sivanesan S, Chang E, Buga AM. ROS and brain diseases: the good, the bad, and the ugly. Oxid Med Cell Longev 2013; 963520.

47. Hassan W, Rongyin G, Daoud A, Ding L, Wang L, Liu J, et al. Reduced oxidative stress contributes to the lipid lowering effects of isoquercitrin in free fatty acids induced hepatocytes. Oxid Med Cell Longev 2014; 3136.

48. Calderón Guzmán D, Osnaya Brizuelan N, Ortíz Herrera M, Hernández García E, Barragán Mejía G, Juárez Olguín H, et al. Effect of cerebrolysin on dopaminergic neurodegeneration of rat with oxidative stress induced by 3-nitropropionic acid. Acta Pharmac 2016; 66:443-448.

\section{Tables}

Table 1. Levels oxidative biomarkers and domamine in brain regions of rats treated with oleic cid (OA) alone or with ciclophosphamide (CPP), daunorrubicine (DRB) and dexrazoxane (DXN). 


\begin{tabular}{|c|c|c|c|c|c|c|c|c|c|c|c|}
\hline & & GSH & & TBARS & & Dopamine & & $\mathrm{H}_{2} \mathrm{O}_{2}$ & & ATPase & \\
\hline Region & Treatment & Mean & SD & Mean & SD & Mean & SD & Mean & SD & Mean & SD \\
\hline \multirow[t]{5}{*}{ Cortex } & Control & 336.849 & 58.55 & 11.082 & 0.96 & 166.98 & 71.85 & 0.028 & 0.012 & 63.32 & 19.91 \\
\hline & OA & 415.958 & 61.05 & 8.920 ** & 2.19 & 270.36 & 101.40 & 0.019 & 0.004 & 58.09 & 18.20 \\
\hline & $\mathrm{CPP}+\mathrm{OA}$ & $569.57 * a$ & 98.92 & $2.125^{\star} \mathrm{a}$ & 0.30 & $2276.04^{* a}$ & 372.11 & 0.026 & 0.005 & 50.36 & 14.78 \\
\hline & $\mathrm{DRB}+\mathrm{OA}$ & $542.24 *$ & 95.81 & $1.772 * a$ & 0.16 & $2112.67^{\star} \mathrm{a}$ & 294.20 & 0.028 & 0.008 & 49.10 & 13.06 \\
\hline & $\mathrm{CDX}+\mathrm{OA}$ & $557.79 *$ & 95.47 & $2.017 * a$ & 0.19 & $2715.99 * a, b$ & 414.40 & 0.031 & 0.004 & 46.85 & 10.21 \\
\hline \multirow[t]{5}{*}{ Striatum } & Control & 769.527 & 167.28 & 15.017 & 1.34 & 272.85 & 103.96 & 0.020 & 0.003 & 128.02 & 41.14 \\
\hline & OA & $606.155 a$ & 106.93 & 14.303 & 2.81 & 360.33 & 112.39 & 0.029 & 0.011 & 109.72 & 27.75 \\
\hline & $\mathrm{CPP}+\mathrm{OA}$ & 855.508 & 105.18 & $3.906 * a$ & 0.58 & $3343.38 * a$ & 776.09 & 0.026 & 0.004 & $75.01 *, a$ & 13.32 \\
\hline & $\mathrm{DRB}+\mathrm{OA}$ & 701.385 & 111.82 & $3.080 * a$ & 0.36 & $2562.25^{\star} a, b$ & 485.31 & 0.030 & 0.006 & 104.79 & 32.12 \\
\hline & $\mathrm{CDX}+\mathrm{OA}$ & 778.960 & 111.11 & $3.551 * a$ & 0.54 & $3299.42 * a$ & 360.68 & 0.032 & 0.011 & 117.24 & 25.83 \\
\hline \multirow[t]{5}{*}{ CMO } & Control & 476.879 & 46.98 & 16.076 & 1.31 & 324.00 & 94.74 & 0.022 & 0.009 & 66.71 & 4.36 \\
\hline & OA & 446.223 & 118.15 & $11.439 *$ & 1.56 & 386.17 & 92.29 & 0.027 & 0.009 & 115.73 & 67.78 \\
\hline & $\mathrm{CPP}+\mathrm{OA}$ & $672.299 a$ & 91.39 & $4.011 * a$ & 0.54 & $2733.62 * a$ & 540.52 & 0.031 & 0.004 & 82.41 & 24.18 \\
\hline & $\mathrm{DRB}+\mathrm{OA}$ & 637.982 & 157.03 & $3.209 * a, b$ & 0.60 & $2223.63^{\star a} a$ & 556.74 & $0.041 * a$ & 0.007 & 91.85 & 18.54 \\
\hline & $\mathrm{CDX}+\mathrm{OA}$ & 480.647 & 152.33 & $5.463^{\star} a$ & 1.02 & $2511.37 * a$ & 572.24 & $0.040 * a$ & 0.006 & 80.64 & 24.10 \\
\hline
\end{tabular}

CMO:Cerebellum/medulla oblongata, SD: Standard Deviation

Glutathione (GSH)

Cortex: Anova $F=6.8774 p=0.0006$. ${ }^{*}<<0.005$ vs control, ${ }^{a} p=0.03$ vs $\mathrm{OA}$

Striatum: Anova $F=3.9468 p=0.0124 .{ }^{a} p=0.007$ vs $C P P+O A$

CMO: $F=4.4578 p=0.0071 .{ }^{a} p<0.05$ vs $O A$ and $C D X+O A$

Lipid peroxidation (TBARS)

Cortex: Anova (Welch) $F=86.7878 p<.0001 .{ }^{*} p<0.0001$ vs control. ${ }^{* \star} p=0.016$ vs control, ${ }^{a} p<0.0001$ vs $0 A$

Striatum: Anova (Welch) $F=78.3615 p<.0001 .{ }^{*} p=<.0001$ vs control, ${ }^{a} p<0.0001$ vs OA

CMO: Anova $F=156.7193 p<.0001{ }^{*} p=0.001$ vs control, ${ }^{a} p<0.0001$ vs $O A{ }^{b} p<0.002$ vs $C D X+O A$

Dopamine

Cortex: Anova (Welch) F=152.1796 $p<0.0001 .{ }^{*} p<0.0001$ vs control, ${ }^{a} p<0.0001$ vs $0 A,{ }^{b} p=0.01$ vs $D R B+O A$

Striatum: Anova (Welch) $F=144.5489 p<.0001 .{ }^{*} p=<.0001$ vs control, ${ }^{a} p<0.0001$ vs $O A,{ }^{b} p=0.04$ vs CPP + OA

CMO: Anova (Welch) $\mathrm{F}=67.3055 \mathrm{p}<0.0001 .{ }^{*} \mathrm{p}=<.0001$ vs control, ${ }^{\mathrm{a}} \mathrm{p}<0.0001$ vs OA

$\mathrm{H}_{2} \mathrm{O}_{2}$

Cortex: Anova $F=2.2322 p=0.0931$

Striatum: Anova $\quad F=2.0085 p=0.1228$ 
CMO: Anova F=8.2568 $p=0.0002 .{ }^{*} p=<0.001$ vs control, ${ }^{a} p<0.01$ vs OA

ATPase

Cortex: Anova F=1.0989 $\quad p=0.3780$

Striatum: Anova $F=3.4580 p=0.0215 .{ }^{*} p=0.03$ vs control, ${ }^{a} p=0.04$ vs $C D X+O A$

CMO: Anova $\mathrm{F}=1.4778 \mathrm{p}=0.2376$.

Table 2. Levels of glucose, hemoglobine and triglycerides in blood of rats treated with oleic acid (OA) alone or with ciclophosphamide (CPP), daunorrubicine (DRB) and dexrazoxane (DXN).

\begin{tabular}{|lllllll|}
\hline & \multicolumn{2}{c}{ Glucose $(\mathrm{mg} / \mathrm{dL})$} & \multicolumn{2}{c|}{ Hemoglobine $(\mathrm{g} / \mathrm{dL})$} & \multicolumn{2}{c|}{ Triglycerides $(\mathrm{mg} / \mathrm{dL})$} \\
\hline Treatment & Mean & Std Dev & Mean & Std Dev & Mean & Std Dev \\
\hline Control & 120.25 & 6.90 & 23.46 & 2.72 & 106.75 & 18.79 \\
\hline Oleic Acid & 122.40 & 8.05 & 23.28 & 3.80 & 102.40 & 4.88 \\
\hline CPP + Oleic acid & 110.63 & 16.13 & $39.02^{*}$ & 3.79 & 99.75 & 17.25 \\
\hline DRB + Oleic acid & 109.14 & 13.07 & $31.90 * a$ & 4.66 & 88.57 & 7.07 \\
\hline CDX + Oleic acid & $145.86 *$ & 13.55 & 28.50 & 0.97 & 101.86 & 26.30 \\
\hline
\end{tabular}

Glucose: Anova F=9.2322 $p<0.0001 .{ }^{*} p<0.03$ vs all treatments.

$\mathrm{Hb}$ : Anova $\mathrm{F}=22.2349 \mathrm{p}<0.0001 .{ }^{*} \mathrm{p}<0.004$ vs all treatments. ${ }^{\mathrm{a}} \mathrm{NS}$ vs $\mathrm{CDX}+\mathrm{OA}$

Triglycerides: Anova F=0.948 p=0.45

\section{Supplementary Files}

This is a list of supplementary files associated with this preprint. Click to download.

- NC3RsARRIVEGuidelinesChecklistfillable.pdf 